\title{
A NEW THEROPOD DINOSAUR FROM THE LOWER CRETACEOUS OF MONTANA
}

JOHN H. OSTROM

Peabody Museum of Natural History and Department of Geology and Geophysics, Yale University

\section{ABSTRACT}

Deinonychus antirrhopus, a new genus and species of theropod dinosaur is described from the Cloverly Formation (Lower Cretaceous) of southern Montana. The species is characterized by a highly specialized pes bearing a very large, trenchant claw on digit II, a highly raptorial manus with a very mobile carpus, and a specialized caudal series with extremely long prezygapophyseal and chevron rods. The new species is closely related to Dromaeosaurus albertensis, which features similar specialization of the second pedal digit, and is referred to the family Dromaeosauridae (=Dromaeosaurinae Matthew and Brown, 1922). Other species with comparable pes structure that may be referred to this family are Stenonychosaurus inequalis, Velociraptor mongoliensis and Saurornithoides mongoliensis. 


\section{INTRODUCTION}

Late in August, 1964, Grant E. Meyer of the Peabody Museum staff and I discovered some fragmentary fossil remains of the species herein described in exposures of the Cloverly Formation (Early Cretaceous) near Bridger, Montana. Extensive quarrying operations during the next two summers recovered more than 1000 bones representing at least three individuals. This collection is the basis of a detailed analysis of the osteology, adaptations and affinities of this remarkable new dinosaurian species (Ostrom, in press).

During the course of the above study, this material was made available to Drs. Edwin H. Colbert of the American Museum of Natural History and Dale A. Russell of the National Museum of Canada, who were collaborating on a new study of Dromaeosaurus albertensis (Matthew and Brown, 1922) from the Oldman Formation of Alberta. This was particularly appropriate because it was evident to each of us that Dromaeosaurus was more closely related to the present species than to any other currently recognized taxon, and any new analysis of Dromaeosaurus would be incomplete without reference to and comparison with the new Yale specimens. At that time it was believed that my detailed analysis establishing this new species would be published well in advance of the study by Colbert and Russell. However, at this writing (December, 1968) a serious possibility exists that such cannot be accomplished. Accordingly, the present brief description of the new species is submitted in order that the name will be available.

Abbreviations used are as follows: AMNH - American Museum of Natural History; YPM - Peabody Museum, Yale University.

\section{SYSTEMATICS}

Class Reptilia

ORDER SAURISCHIA

Suborder Theropoda Marsh, 1881

Family Dromaeosauridae (=Dromaeosaurinae Matthew

and Brown, 1922)

DEFINITION: Small to moderate-sized theropods, lightly built and bipedal in posture. Fore limb not reduced. Manus long and slender 
with three functional digits. Digit III moderately divergent and carpus highly specialized with asymmetrical ginglymus on radiale. Hind limb long, pes of moderate length and functionally didactyl. Digit II modified as an offensive or predatory weapon with large, trenchant claw. Digits III and IV subequal and normal, digits I and $\mathrm{V}$ reduced. Eight to 9 cervical vertebrae, 13 to 14 dorsals and 3 to 4 sacrals. Caudal series of Deinonychus highly modified by extremely long prezygapophyseal and chevron processes which rendered the tail virtually inflexible throughout most of its length. Comparable caudal modifications are presumed, but not known, in other taxa referred to the family.

Distribution: Late Aptian to Late Campanian or Early Maestrichtian, western interior of North America and central Mongolia.

Deinonychus, new genus

TYPE SPECIES: Deinonychus antirrhopus, new species.

Distribution: Late Aptian, south central Montana.

DIAGNOSIS: Same as for the species, given below.

ETYMology: Deinos (Greek), terrible, and onyx (Greek; masculine), claw or talon.

Deinonychus antirrhopus, new species

TYPE: YPM 5205, a complete left pes and an incomplete right pes.

HYPODIGM: YPM 5201, 5202, and 5203, three series of articulated caudal vertebrae.

YPM 5204, part of the atlas, the axis, fourth and fifth cervicals and the fourth, sixth, seventh and ninth dorsals.

YPM 5206, nearly complete left and right manus.

YPM 5210, an incomplete skull and jaws (vomers, left and right quadratojugals, both squamosals, a left articular, left and right pterygoids, a right ectopterygoid, right surangular, left jugal, right angular, left dentary, and numerous teeth), the atlas, axis and 
seventh cervical, the first and tenth dorsals and an anterior (3rd or 4th) caudal.

YPM 5232, consists of the right maxilla, right and left nasals, right and left dentary, right and left (incomplete) premaxillae, right and left jugals, right squamosal, both postorbitals, right lachrymal, right and left articulars, left palatine, left angular and right quadratojugal.

YPM 5207，5208，5209，5211-5231，5233-5265, various isolated and fragmentary elements.

AMNH 3015, an incomplete skeleton, lacking the skull and jaws.

AMNH 3037, fragmentary bones from the manus and pes.

HORIZON: Cloverly Formation, lower part of Unit VII (=upper part of Himes member of Moberly, 1960) and upper part of Unit V (=Little Sheep mudstone member of Moberly, 1960), ranging from 50 to 100 feet below the Sykes Mountain Formation. (Units $\mathrm{V}$ and VII are defined in my report on the stratigraphy and paleontology of the Cloverly Formation [Ostrom, MS]).

LOCalities: YPM 64-75 - NE 1/4 Sec. 17, T.7 S., R.24 E., Carbon County, Montana. AMNH 31-7 - NW 1/4 Sec. 33, T.4 S., R.29 E., Big Horn County, Montana. AMNH 32-8 - NE 1/4 Sec. 32, T.4 S., R.29 E., Big Horn County, Montana.

DIAGNOSIS: A small, bipedal theropod with moderately large head, moderately long and well developed hind limbs, fore limbs not reduced, Inanus long and slender. Pes of medium length with four digits, the fifth represented by a vestigial metatarsal. Digital formula of the pes 2-3-4-5-0. Digits III and IV equal in length and normal, digit II specialized and bearing a very large, trenchant and strongly recurved ungual, I reduced and directed backward. Pes functionally didactyl (III and IV). Distal end of metatarsal II deeply grooved, metatarsal III not greatly compressed proximally. Articular facets of II developed to permit unusual extension but very little flexion between first and second phalanges. Manus with three very long digits (formula 2-3-4), digits IV and $\mathrm{V}$ lost. Metacarpal I short and irregular in shape. Metacarpal III long, slender and divergent from II. Carpus consists of radiale 
and ulnare only. Radiale with well defined asymmetrical ginglymus proximally for articulation with radius. Humerus and radius-ulna not reduced. Skull with large, circular orbit and three antorbital fenestrae. Supraorbital rugosities on postorbital and lachrymal. Preorbital bar slender, in weak contact with thin, plate-like jugal. Quadratojugal very small, T-shaped and apparently not in contact with squamosal. Nasals long, narrow and unfused. Inferior premaxillary process forms lower margin of external naris. Pterygoid very long and slender, ectopterygoid complex and pocketed ventrally. Palatines expanded with subsidiary palatine fenestrae medially. Fifteen maxillary teeth, 4 asymmetrical, sub-incisiform, premaxillary teeth, 16 sub-isodont dentary teeth. All teeth with anterior and posterior serrations; denticles of posterior serrations nearly twice as large as denticles of anterior serrations on all teeth. Twenty-two or 23 presacral vertebrae, 3 or 4 sacrals and approximately 40 caudals. Cervical vertebrae of moderate length, massive, platycoelous and sharply angled. Dorsals short and platycoelous to amphiplatyan with well developed hyposphene-hypantrum and bearing short, stout neural spines. All presacrals with small but deep pleurocoels. Caudal vertebrae long and platycoelous. All caudals except the first 8 or 9 bear extremely long (up to 10 segments), rod-like, prezygapophyseal processes. Chevrons also elongated into long, paired, double, bony rods extending forward beneath the preceding 8 or 9 segments. Ischium with triangular obturator process. Pubis (if correctly identified) short and greatly expanded into a sub-circular, scoop-shaped element with a distinct obturator foramen.

ETYMOLOGY: antirrhopus (Greek; masculine), counterbalancing, in reference to the unusual adaptation of the caudal vertebrae.

\section{Discussion}

The above diagnosis is based on the hypodigm and not on the type alone. The fossil remains recovered from the Yale site were closely associated, but largely disarticulated. The most notable exceptions are the three articulated caudal series (YPM 5201, 5202 and 5203), a complete left pes and a fragmentary right pes (YPM 5205), and a nearly complete left manus (YPM 5206). Because more than one individual is represented, it is impossible 
to establish definite individual associations of the disarticulated elements. Accordingly, the collections from this site have been catalogued as more than 50 separate entries, although in fact they may represent as few as three individuals. There is no doubt in my mind that these remains belong to a single species and I have thus based my diagnosis on the entire Yale sample, plus two fragmentary specimens in the American Museum collections (AMNH 3015 and 3037).

The most distinctive features of Deinonychus are the pes, carpus, manus and caudal vertebrae. Each of these structures indicate an animal of great agility and speed and a highly predaceous mode of life.

The pes is basically tridactyl in design (although a reduced hallux and a remnant of metatarsal $\mathrm{V}$ are present), but the foot functioned as a didactyl structure in locomotion (Fig. 1). The weight-bearing axis of the foot has been shifted from the normal theropod position at digit III to a position between digits III and IV. Metatarsal IV is distinctly shorter than III, but digits III and IV are equal in length, reflecting the fact that the weight was borne equally by these two digits.

The second digit is highly specialized for a non-locomotory, predatory function and quite probably did not contact the ground at all under normal circumstances. The ungual of the second digit is more than twice the size of the other unguals and is very strongly recurved and trenchant in contrast to the straighter and broader form of unguals III and IV (Fig. 2). Associated with this unusual sickle-like claw of digit II are several other peculiar specializations of the second digit. The distal joint is a very deeply grooved ginglymus that permitted considerable flexion of the ungual (note the very deep, parallel-sided articular facet of the ungual in Fig. $2 \mathrm{a}$, but little extension. The joint between the proximal and penultimate phalanges, on the other hand, permitted no flexion, but allowed excessive $\left(90^{\circ}\right.$ or more) extension (note the proximal "heel" or projection of the distal phalanx and the unusual elevation of the distal facet of the proximal phalanx in Fig. 3). This appears to be a unique adaptation for elevation of the sickle-like claw above the ground, perhaps to prevent its damage during normal locomotion. This joint, like the distal articulation, is an unusually deeply grooved ginglymus (Fig. 3 ). 
The distal end of metatarsal II is also unusual in that it is deeply grooved, forming an asymmetrical ginglymus that had not been recognized before in any other theropod. It is evident from the deeply grooved form of all three joints that the second pedal digit of Deinonychus was adapted for flexion and extension in a narrowly restricted plane, and this seems to have been related to the unusual size and recurved, trenchant form of the claw.

The manus is of the usual tridactyl form characteristic of most theropod species. It differs from most, however, in its unusual length and the relative size and trenchant, raptorial form of the unguals (Figs 4 and 5). Digit III is unusual in its slender form and the fact that it apparently could be deflected away from the other digits, although it probably was not opposable in the usual sense.

The carpus consists of only two elements, ulnare and radiale; these were highly modified to produce precisely limited abductionadduction and supination-pronation. The proximal facet of the radiale is a strongly asymmetrical ginglymus that permitted perhaps as much as $100^{\circ}$ of abduction-adduction, and during the final phases of abduction approximately 35 to $45^{\circ}$ of supination (Fig. 6). The proximal facet of the much smaller ulnare is a simple oval concavity that could have permitted rotation of the carpus and manus about the ulna long axis, as well as adductionabduction or flexion and extension. These highly sophisticated movements of the wrist are entirely consistent with the raptorial design of the manus.

The caudal vertebrae of Deinonychus are remarkable in the extreme modification of the chevrons and prezygapophyses (Figs. 7 and 8 ). Posterior to the ninth or tenth caudal the chevrons are not blade-like ventral processes, but are flat, wedge-shaped elements pointing caudally. The anterolateral corners of these wedges are drawn out into long, double rods reaching lengths of eight to ten segments. These rods, ranging from approximately $2 \mathrm{~mm}$ to less than $0.2 \mathrm{~mm}$ in diameter, are preserved in bundles lying lateral to the lower half of the caudal centra. The prezygapophyses are correspondingly elongated into double rods extending forward as much as 10 segments. These are identical in size, shape and surface texture to the chevron rods and occupy a comparable position lateral to the neural arches. Both structures are 
present on all distal caudals; only the first eight or nine caudals lacked them. Both rod types probably developed by ossification of tendons associated with flexor and extensor muscles of the tail and appear to have been an adaptation for controlled stiffening of the tail. This feature seems best explained as an adaptation for balancing, a critical faculty in an obligatory biped.

I have placed Deinonychus in the Dromaeosauridae because of the almost identical form of the pes of Deinonychus and Dromaeosaurus. The latter is described in detail by Colbert and Russell (in press), and is not discussed further here. Other taxa that appear to be closely allied with Deinonychus on the basis of pes structure are: Stenonychosaurus inequalis Sternberg (1932), Velociraptor mongoliensis Osborn (1924), and Saurornithoides mongoliensis Osborn (1924). Accordingly, these are referred to the Dromaeosauridae. Further discussion of these assignments is included in my study of the osteology of Deinonychus that is now in press.

\section{ACKNOWLEDGMENTS}

I am grateful to Drs. Edwin H. Colbert and Dale A. Russell for many hours of stimulating discussion about Deinonychus and its allies. I also thank Dr. Colbert for permission to include the two American Museum specimens in this study and for providing Barnum Brown's field records pertaining to these specimens. The photographs were taken by A. H. Coleman and the manuscript was typed by Louise Holtzinger.

The discovery and collection of the Yale Deinonychus material was possible only because of grants from the National Science Foundation (GB-1015 and GB-3638), which are gratefully acknowledged.

\section{Literature Cited}

Colbert, Edwin H., and Dale A. Russell. [In press]. The small Cretaceous dinosaur, Dromaeosaurus. Amer. Mus. Novitates.

Marsh, Othniel C. 1881. Principal characters of American Jurassic dinosaurs. Pt. V. Amer. Jour. Sci., Ser. 3, 21 : 417-423.

Matthew, William D., and Barnum Brown. 1922. The family Deinodontidae, with notice of a new genus from the Cretaceous of Alberta. Bull. Amer. Mus. Nat. Hist. 46: 367-385.

Moberly, Ralph, Jr. 1960. Morrison, Cloverly and Sykes Mountain Formations, northern Bighorn Basin, Wyoming and Montana. Bull. Geol. Soc. Amer. 71: 1137-1176. 
Osborn, Henry Fairfield. 1924. Three new Theropoda, Protoceratops zone, central Mongolia. Amer. Mus. Novitates, no. 144: 1-12.

Ostrom, John H. [In press]. Osteology of Deinonychus antirrhopus, an unusual theropod from the Lower Cretaceous of Montana. Bull. Peabody Mus. Nat. Hist.

[MS] [Stratigraphy and palcontology of the Cloverly Formation (Lower Cretaceous) of the Bighorn Basin area, Wyoming and Montana.]

Sternberg, Charles M. 1932. Two new theropod dinosaurs from the Belly River Formation of Alberta. Canadian Field Naturalist 46: 99-105. 


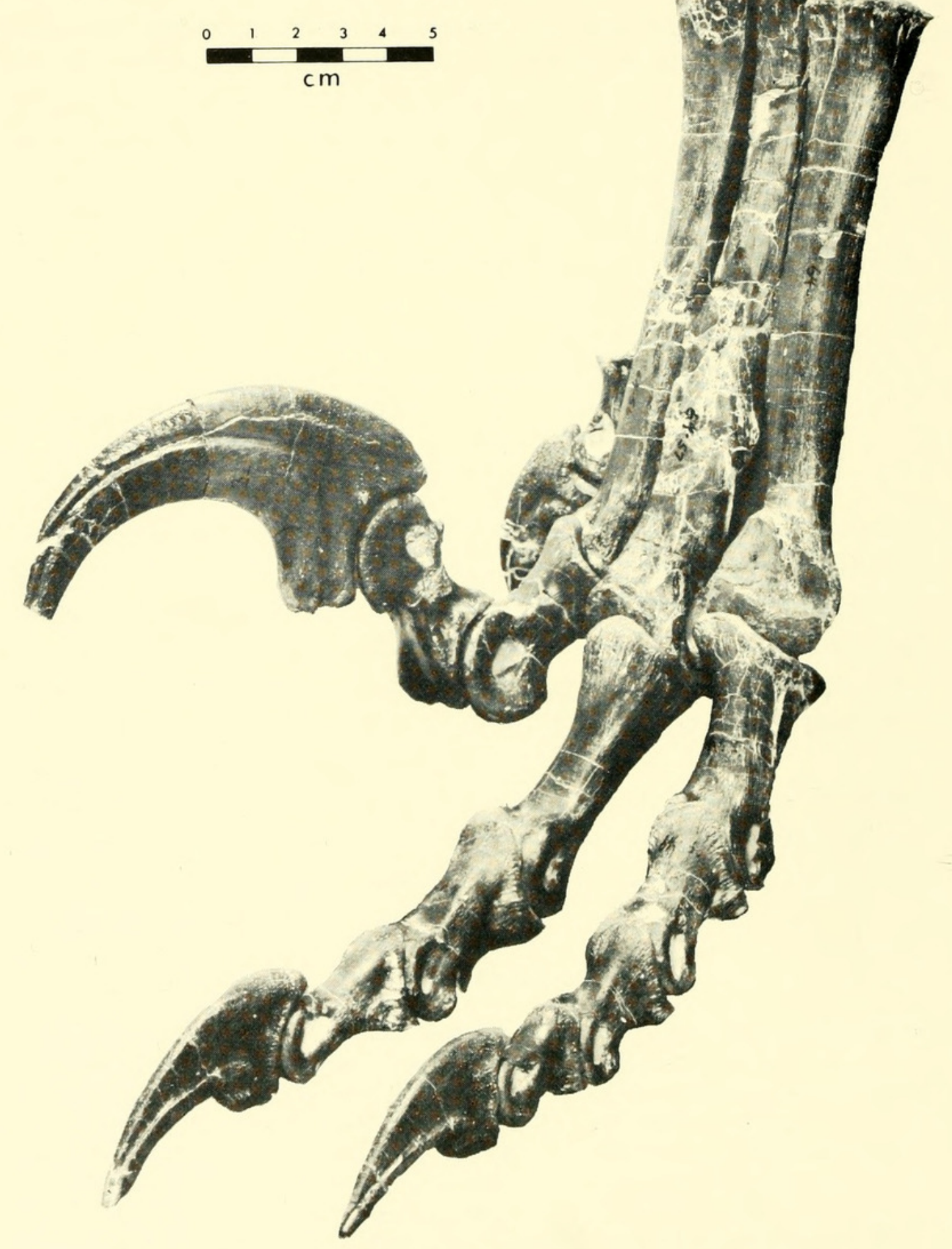

FIG. 1. Left pes of Deinonychus antirrhopus, YPM 5205 (type). 
A
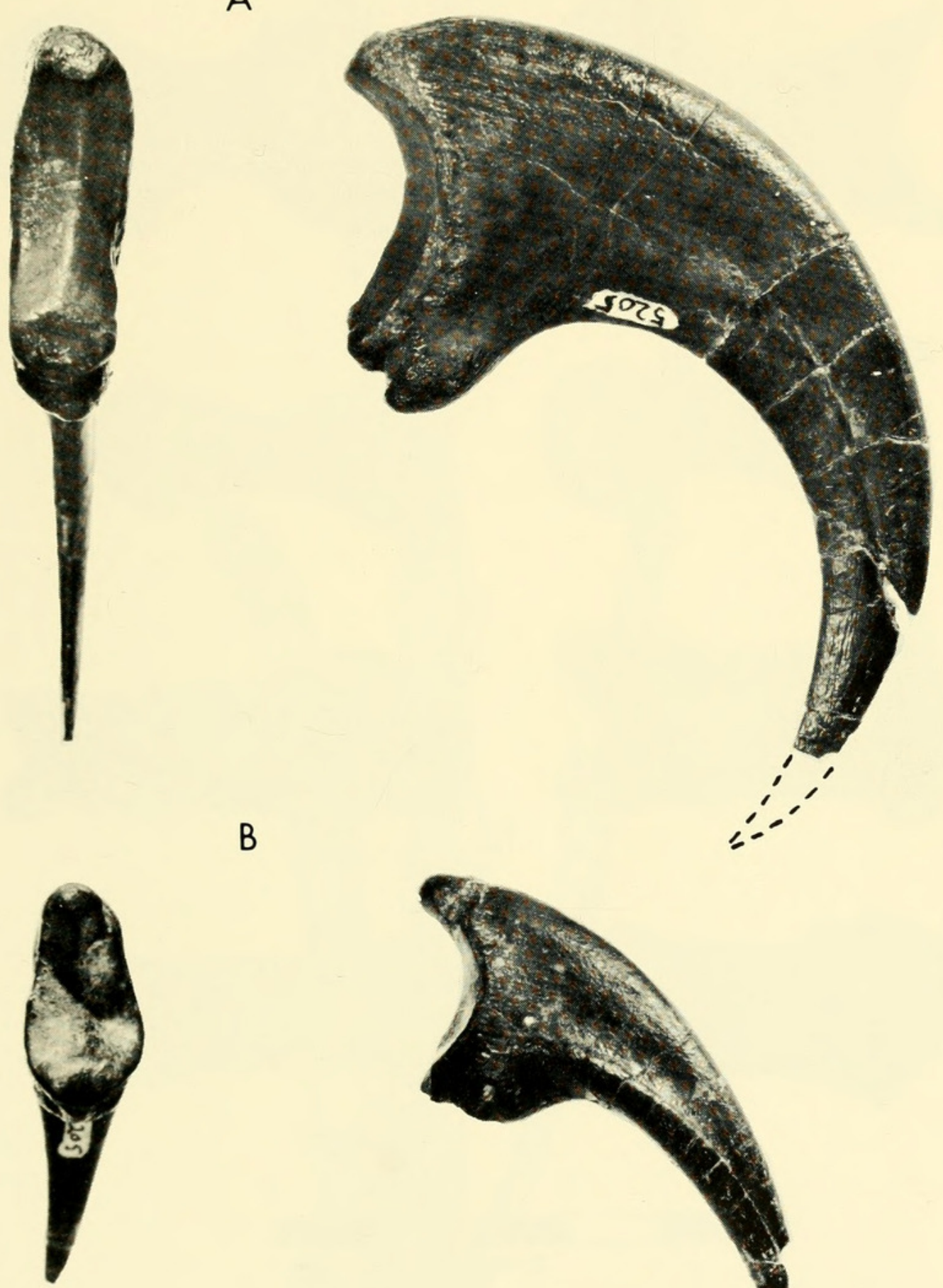

B

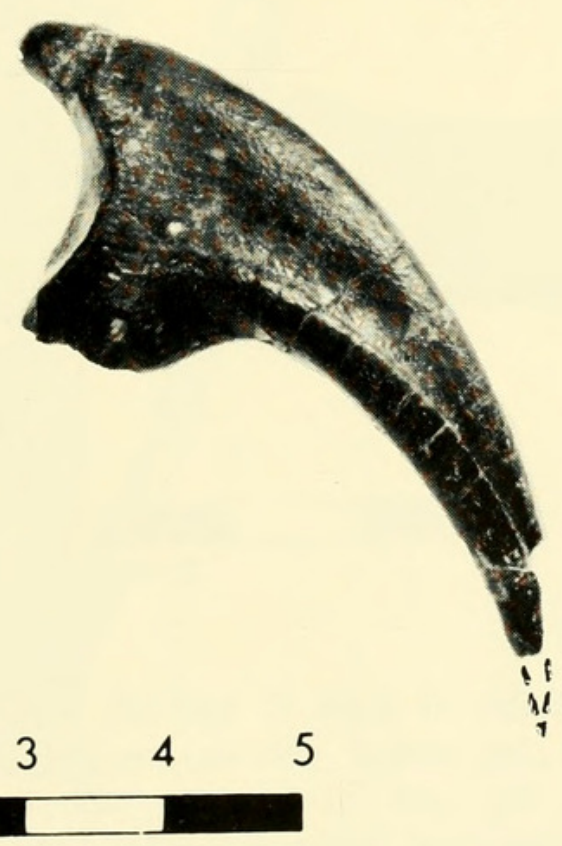

c m

FIG. 2. Unguals of digits II (A) and III (B), left pes of Deinonychus antirrhopus (YPM 5205), in medial (right) and proximal (left) views. Notice the very long, narrow, parallel-sided articular facet of ungual II. 

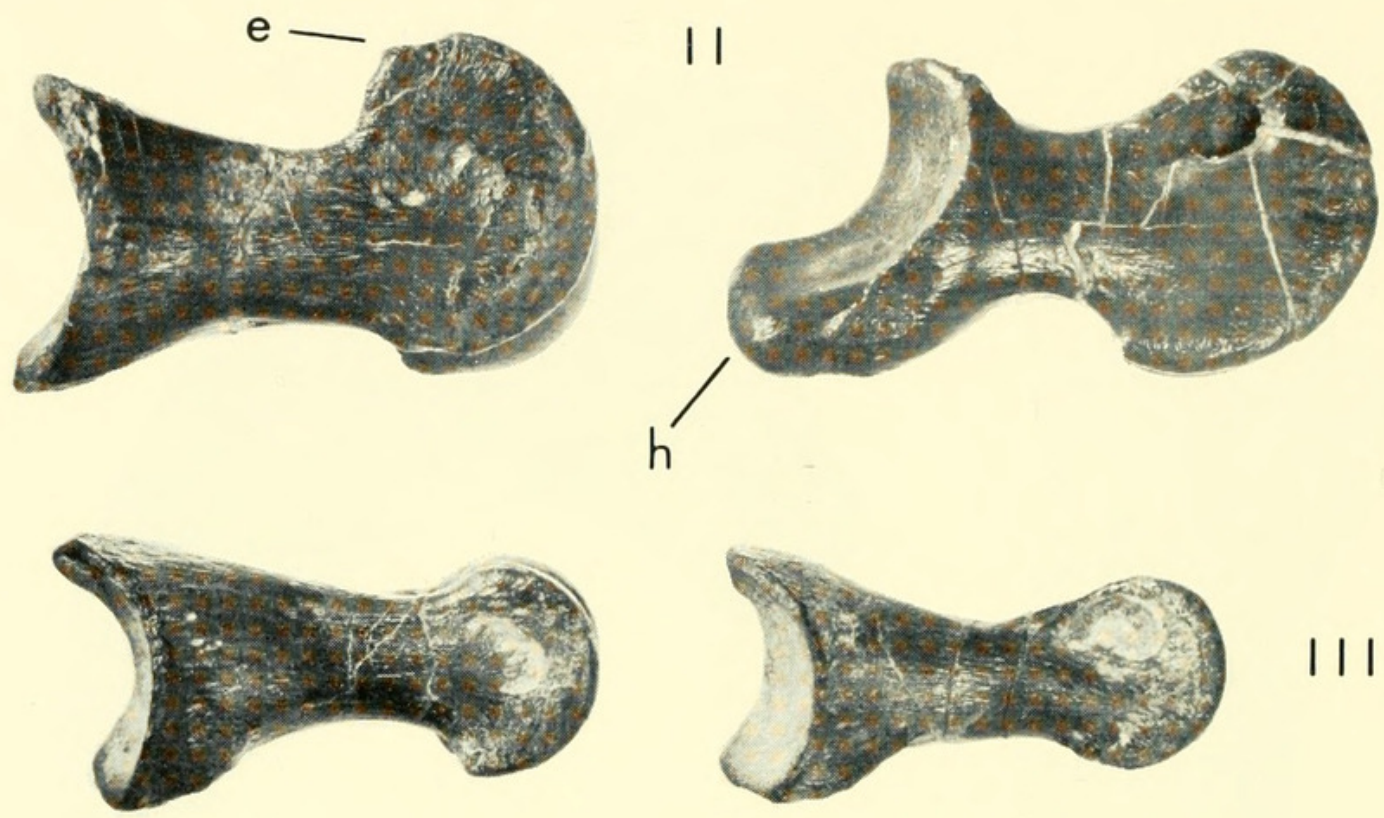

| 1
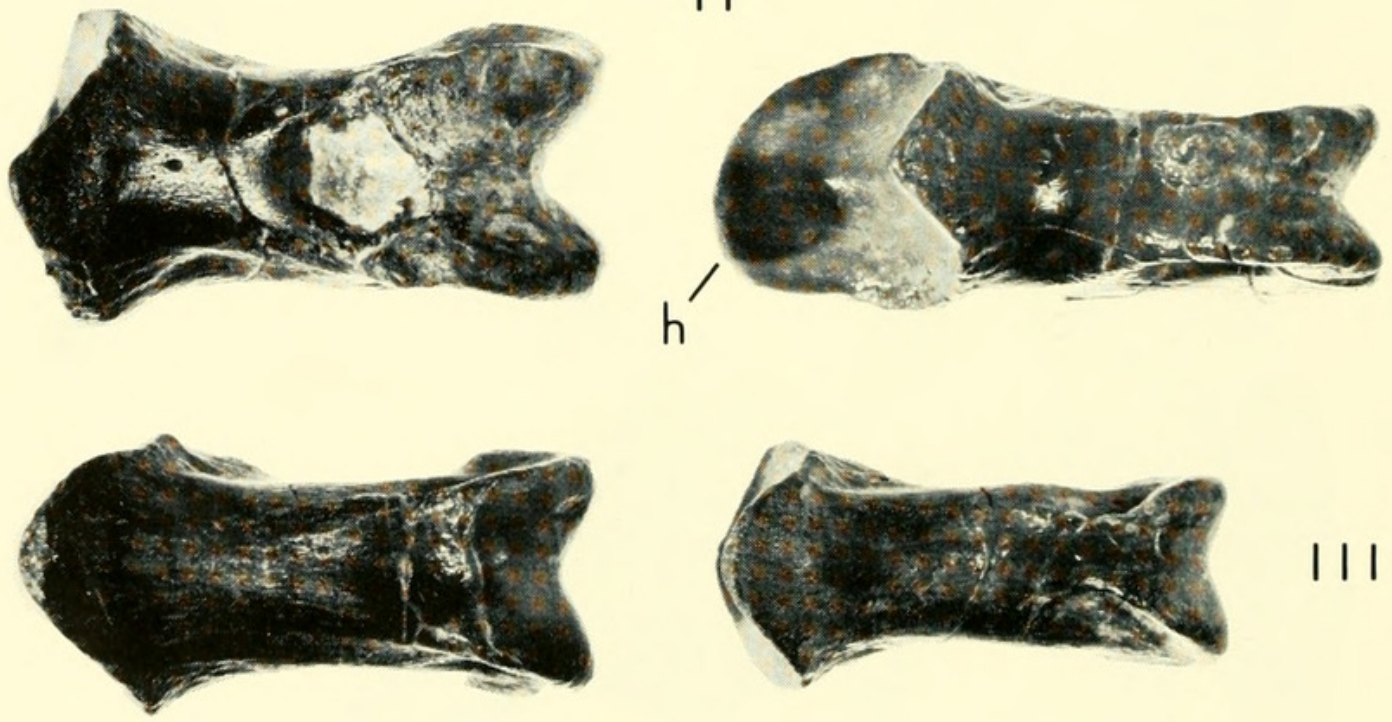

|| $\mid$

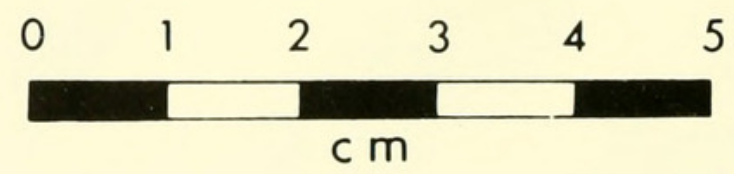

FIG. 3. Phalanges of digits II and III, left pes of Deinonychus antirrhopus (YPM 5205), in medial (above) and dorsal (below) views. Penultimate phalanx is on the right in all series, adjacent (proximal) phalanx is at left. Notice the prominent ventroproximal expansion or heel $(h)$ of the distal phalanx of II, and the unusual elevation (e) of the distal facet of the adjacent phalanx. Together these restricted flexion, but permitted extreme extension (as shown in Fig. 1). Compare these features with those of the equivalent phalanges of digit III. Notice also in the dorsal views the deeper grooves of the ginglymoid facets of the second phalanges compared with the phalanges of III. 


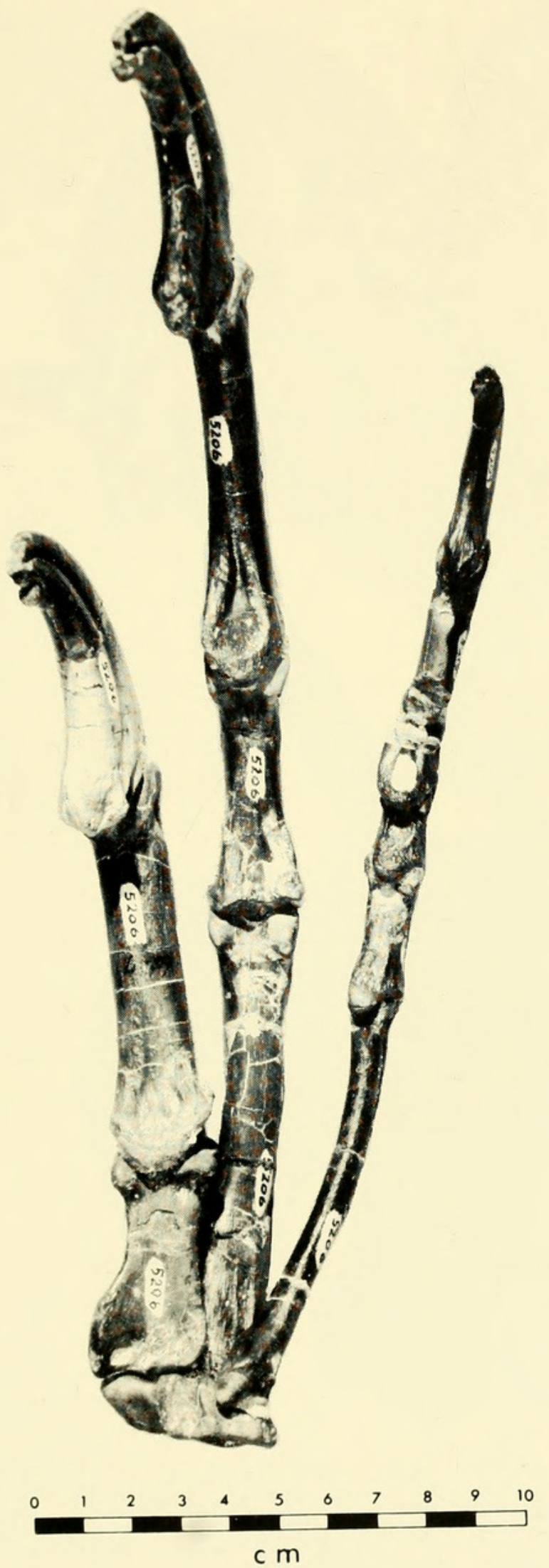

FIG. 4. Left manus of Deinonychus antirrhopus (YPM 5206) in palmar view. 


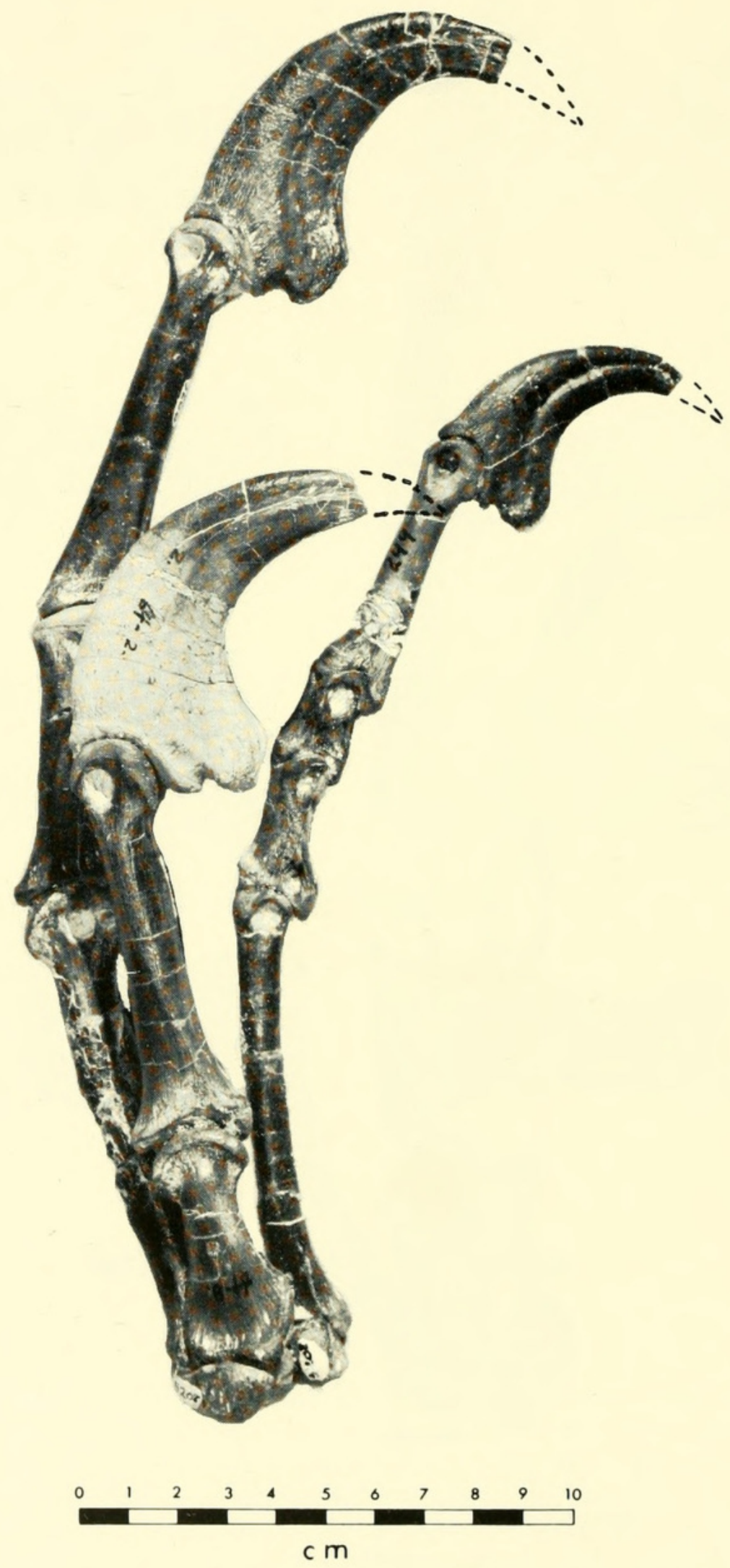

FIG. 5. Left manus of Deinonychus antirrhopus (YPM 5206) in medial view. Notice the unusual size and raptorial form of the unguals. 


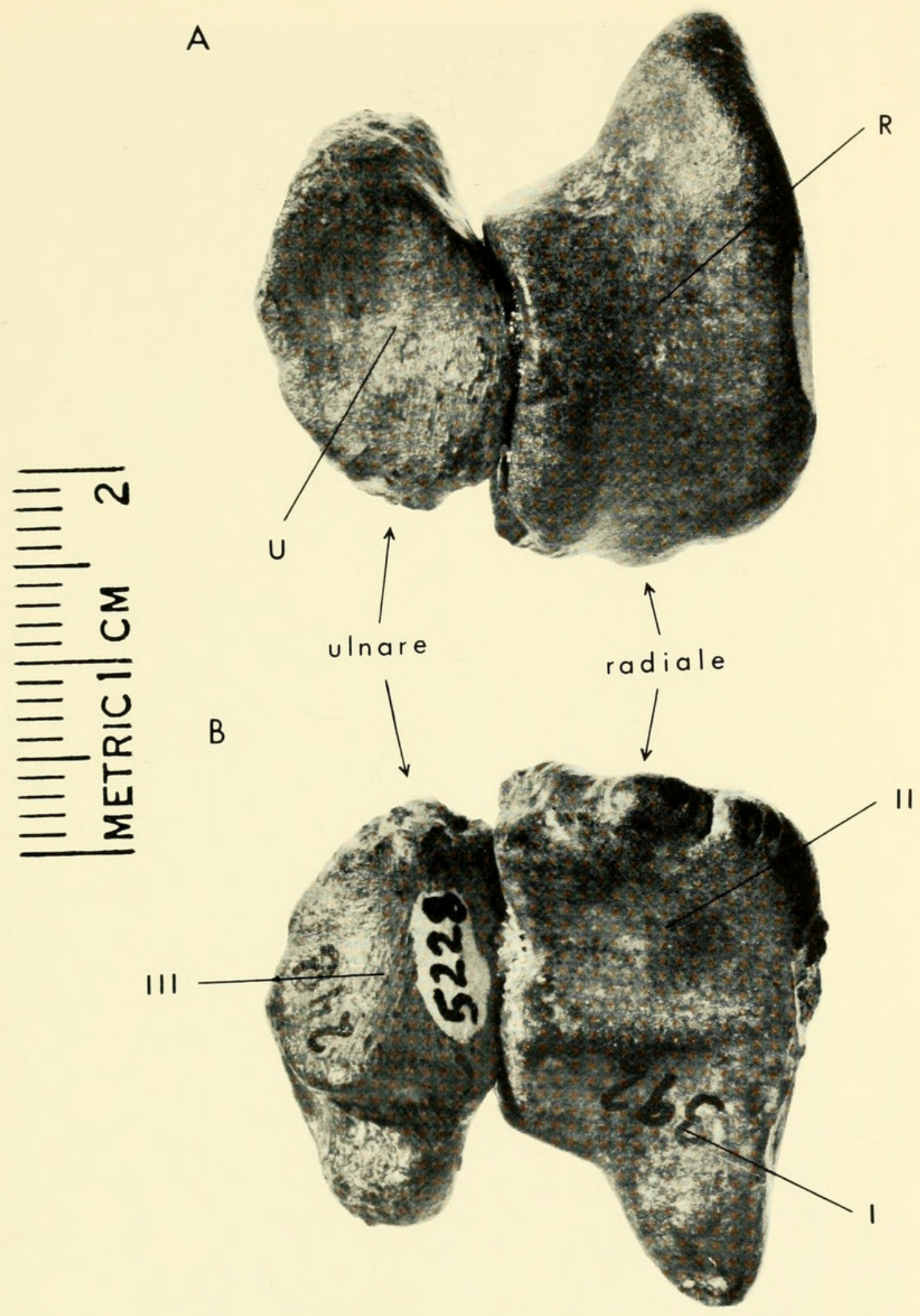

FIG. 6. Proximal (A) and distal (B) views of the right carpals of Deinonychus antirrhopus (YPM 5228). Notice the asymmetrical ginglymus on the proximal surface of the radiale. The distal surfaces show distinct facets for metacarpals I and II on the radiale and a sharply curved facet for III on the ulnare. Abbreviations: $\mathrm{R}$ - facet for radius; $\mathrm{U}$ - facet for ulna; I, II, III - facets for metacarpals. 


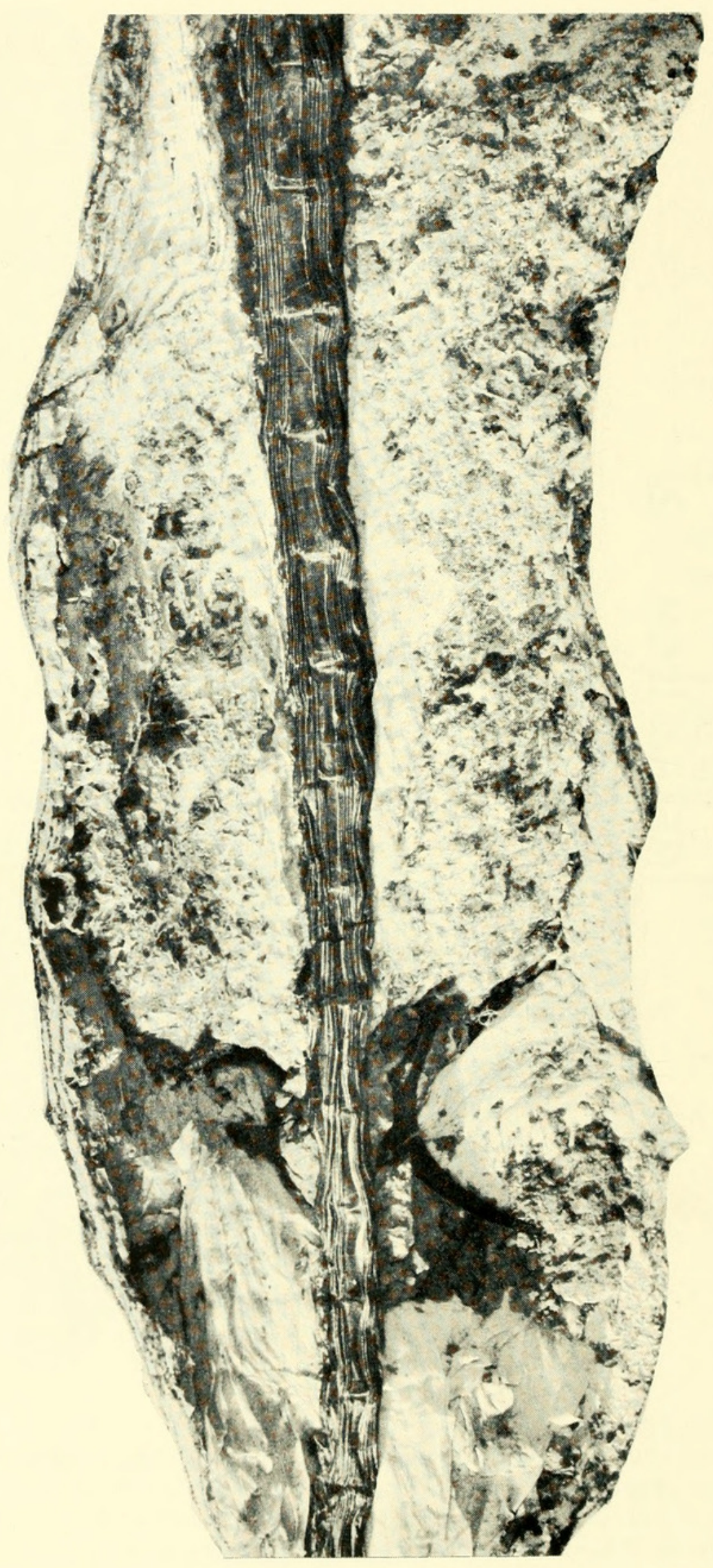

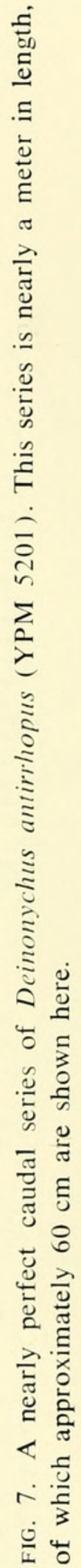




\section{$2 \mathrm{BHL}$ Biodiversity Heritage Library}

Ostrom, John H. 1969. "A new theropod dinosaur from the Lower Cretaceous of Montana." Postilla 128, 1-17.

View This Item Online: https://www.biodiversitylibrary.org/item/40527

Permalink: https://www.biodiversitylibrary.org/partpdf/83223

\section{Holding Institution}

Harvard University, Museum of Comparative Zoology, Ernst Mayr Library

\section{Sponsored by}

Harvard University, Museum of Comparative Zoology, Ernst Mayr Library

\section{Copyright \& Reuse}

Copyright Status: In copyright. Digitized with the permission of the rights holder.

Rights Holder: Yale Peabody Museum of Natural History

License: http://creativecommons.org/licenses/by-nc-sa/3.0/

Rights: https://biodiversitylibrary.org/permissions

This document was created from content at the Biodiversity Heritage Library, the world's largest open access digital library for biodiversity literature and archives. Visit BHL at https://www.biodiversitylibrary.org. 